\title{
Antibiotic Sensitivity Pattern of Escherichia coli from Catheter- Associated Urinary Tract Infections (CAUTI) at Intensive Care Unit
}

\author{
Achmad Iqbal Uswanas ${ }^{1}$, Rebekah Juniati Setiabudi²*, Wahjoe Djatisoesanto ${ }^{3}$ \\ rebekahsetiabudi@gmail.com \\ ${ }^{I}$ Medical Program, , Faculty of Medicine Airlangga University 60132, Surabaya, East Java, Indonesia \\ ${ }^{2}$ Department of Clinical Microbiology, Faculty of Medicine Airlangga University 60132 - Dr. Soetomo General Academic Hospital, \\ Surabaya, East Java, Indonesia \\ ${ }^{3}$ Department of Urology, Faculty of Medicine Airlangga University 60132 - Dr. Soetomo General Academic Hospital, Surabaya, East \\ Java, Indonesia
}

\begin{abstract}
Background: UTI is a common infection case found in the community and hospital. Hospital-acquired UTIs are often caused by antibiotic-resistant microorganisms. This study aims to provides an overview of the sensitivity of various antibiotics to Escherichia coli from isolates of UTI patients using urethral catheters at the intensive care unit Dr. Soetomo General Academic Hospital Surabaya. Method: This type of research is a retrospective descriptive using medical records and the research sample was taken by the total sampling method. The research variables were gender, age, and antibiotics. Result: During the period January 2018 - December 2019, there were 31 intensive care patients who met the inclusion criteria. $25(80.6 \%)$ patients were female and $9(29 \%)$ elderly patients ranged in age from 46 to 65 years. Escherichia coli causing UTI $21(67.7 \%)$ ESBL producing group. Escherichia coli that produce ESBL sensitive to tetracycline antibiotics. Non-ESBL Escherichia coli sensitive to aminoglycoside, quinolone, tetracycline, macrolides, folate pathway antagonist, and others. Conclusion: Inappropriate use of antibiotics has an impact on the rapid spread of antibiotic-resistant microorganisms in the intensive care environment in the future.
\end{abstract}

Keywords: sensitivity pattern, antimicrobial, Escherichia coli, ESBL, CAUTI, nosocomial infection, intensive care unit ;

\section{Introduction}

Urinary Tract Infection (UTI) caused by the use of a urethral catheter is a common nosocomial case and is commonly known as Catheter-associated Urinary Tract Infections (CAUTI). CAUTI occurred at $2.3-4.4$ per 1000 days of urethral catheter use and was the second most common (28.4\%) DAI (Device-associated Infection) in intensive care [1].

Risk factors for UTI include female gender, previous history of UTI, sexual activity, vaginal infections, diabetes, obesity, HIV/AIDS, and immune system disorders [2]. Escherichia coli are the cause of 70\%-95\% of UTI cases [3]. The risk factors for beta-lactamase in UTI isolates were $83.3 \%$ urethral catheter use, $72.7 \%$ ICU admission, and $65.3 \%$ previous use of antibiotics within 3 months [4].

Appropriate UTI management needs to be done to prevent recurrent UTIs and complications that can occur, such as persistent bacteriuria, bacteremia, and urosepsis. In addition, acute necrotic infection of the kidney may occur due to recurrent UTIs [5]. The antibiotic commonly used as empiric therapy in cases of UTI is ceftriaxone which shows a resistance rate of $71.4 \%$ [6]. The presence of mutations from bacteria that cause 
UTIs based on different times and places allows the presence of bacteria with Antimicrobial Resistance (AMR). This can have an impact, such as increased morbidity, medical costs, and mortality. The purpose of this study was to describe the sensitivity of various antibiotics to Escherichia coli from isolates of CAUTI patients at the intensive care unit of Dr. Soetomo General Academic Hospital Surabaya.

\section{Method}

This type of research is a retrospective descriptive using medical records of CAUTI patients caused by Escherichia coli at the intensive care unit of Dr. Soetomo General Academic Hospital period January 2018December 2019. The research sample was taken using a total sampling method that met the inclusion criteria and then described qualitatively.

The research variables were gender, age, and antibiotics. The antibiotic variable is the type of antibiotic that has been tested for sensitivity in CAUTI patients caused by Escherichia coli. The sensitivity test was carried out based on the availability of antibiotic discs, Standard Operating Procedure (SOP) in the Department / SMF of Clinical Microbiology, and referring to The Clinical \& Laboratory Standards Institute (CLSI). This study was approved by the health research ethics committee of Dr. Soetomo General Academic Hospital by issuing Letter of Exemption (0250/LOE/301.4.2/XII/2020).

\section{Result}

During the period January 2018-December 2019, a total of 31 samples of CAUTI patients caused by Escherichia coli were obtained based on microbiological examinations.

\section{Gender}

CAUTI patients caused by Escherichia coli in intensive care unit by gender $25(80.6 \%)$ patients were female and $6(19.4 \%)$ patients were male.

Table 1. Frequency distribution based on patient gender

\begin{tabular}{ccc}
\hline Gender & Frequency (n) & Percentage (\%) \\
\hline Male & 6 & 19.4 \\
Female & 25 & 80.6 \\
\hline Total & 31 & 100 \\
\hline
\end{tabular}

\section{Age}

CAUTI patients caused by Escherichia coli in the intensive care unit by age group; dominated by $9(29 \%)$ elderly patients aged $46-65$ years, and at least $1(3.2 \%)$ toddler patients aged $5-11$ years.

Table 2. Frequency distribution based on patient age

\begin{tabular}{ccc}
\hline Age & Frequency $(\mathbf{n})$ & Percentage $(\%)$ \\
\hline $\mathbf{0}-\mathbf{5}$ (Toddler) & 2 & 6.5 \\
$\mathbf{5}-\mathbf{1 1}$ (Child) & 1 & 3.2 \\
$\mathbf{1 2}-\mathbf{2 5}$ (Teenager) & 6 & 19.4
\end{tabular}




\begin{tabular}{ccc}
$\mathbf{2 6}-\mathbf{4 5}$ (Adult) & 6 & 19.4 \\
$\mathbf{4 6}-\mathbf{6 5}$ (Elderly) & 9 & 29 \\
$\mathbf{>} \mathbf{6 5}$ (Old) & 7 & 22.6 \\
\hline Total & 31 & 100 \\
\hline
\end{tabular}

\section{Antibiotics}

CAUTI patients caused by Escherichia coli in the intensive care unit based on ESBL-producing and nonESBL groups showed Escherichia coli 21 (67.7\%) in the ESBL-producing group and 10 (32.3\%) non-ESBL groups.

Table 3. Frequency distribution based on ESBL and non-ESBL producers

\begin{tabular}{ccc}
\hline Escherichia coli group & Frequency (n) & Percentage (\%) \\
\hline ESBL & 21 & 67.7 \\
Non-ESBL & 10 & 32.3 \\
\hline Total & $\mathbf{3 1}$ & $\mathbf{1 0 0}$ \\
\hline
\end{tabular}

Escherichia coli that produce ESBL $85.7 \%$ are sensitive to tetracycline antibiotics. 100\% of ESBLproducing Escherichia coli are resistant to aminoglycoside antibiotics, beta-lactam penicillin, beta-lactam cephalosporins, folate pathway antagonists, chloramphenicol, quinolones, others, and $89.5 \%$ are resistant to macrolides antibiotics.

The results also showed that non-ESBL Escherichia coli were 100\% sensitive to aminoglycoside and quinolone antibiotics, $90 \%$ sensitive to tetracycline antibiotics, macrolides, and others. $80 \%$ sensitive to folate pathway antagonist antibiotics. $100 \%$ of non-ESBL Escherichia coli are resistant to penicillin beta-lactam antibiotics, beta-lactam cephalosporins, and $75 \%$ are resistant to chloramphenicol group antibiotics.

Table 4. Antibiotic sensitivity pattern of Escherichia coli from CAUTI at intensive care unit

\begin{tabular}{|c|c|c|c|c|c|c|c|c|c|c|c|c|c|c|c|}
\hline \multirow{4}{*}{ No } & \multirow{4}{*}{ Antibiotic } & \multicolumn{14}{|c|}{ Escherichia coli } \\
\hline & & \multicolumn{7}{|c|}{ ESBL } & \multicolumn{7}{|c|}{ Non-ESBL } \\
\hline & & \multirow{2}{*}{ Total } & \multicolumn{2}{|c|}{$\mathbf{S}$} & \multicolumn{2}{|c|}{ I } & \multicolumn{2}{|c|}{$\mathbf{R}$} & \multirow{2}{*}{ Total } & \multicolumn{2}{|c|}{$\mathbf{S}$} & \multicolumn{2}{|c|}{ I } & \multicolumn{2}{|c|}{$\mathbf{R}$} \\
\hline & & & $\mathbf{n}$ & $\%$ & $\mathbf{n}$ & $\%$ & $\mathbf{n}$ & $\%$ & & $\mathbf{n}$ & $\%$ & $\mathbf{n}$ & $\%$ & $\mathbf{n}$ & $\%$ \\
\hline \multicolumn{16}{|c|}{ Aminoglycoside } \\
\hline 1 & AMI & 20 & 1 & 5 & 0 & 0 & 19 & 95 & 9 & 6 & 66.7 & 2 & 22.2 & 1 & 11.1 \\
\hline 2 & TOB & 20 & 19 & 95 & 1 & 5 & 0 & 0 & 10 & 10 & 100 & 0 & 0 & 0 & 0 \\
\hline 3 & $\mathrm{CN}$ & 21 & 0 & 0 & 0 & 0 & 21 & 100 & 9 & 2 & 22.2 & 0 & 0 & 7 & 77.8 \\
\hline 4 & STM & 19 & 0 & 0 & 0 & 0 & 19 & 100 & 10 & 9 & 90 & 0 & 0 & 1 & 10 \\
\hline \multicolumn{16}{|c|}{ Beta-lactam Penicillin } \\
\hline 5 & ATM & 9 & 7 & 77.8 & 0 & 0 & 2 & 22.2 & 1 & 0 & 0 & 0 & 0 & 1 & 100 \\
\hline 6 & AMC & 21 & 0 & 0 & 0 & 0 & 21 & 100 & 10 & 9 & 90 & 0 & 0 & 1 & 10 \\
\hline 7 & AMP & 1 & 0 & 0 & 0 & 0 & 1 & 100 & 0 & 0 & 0 & 0 & 0 & 0 & 0 \\
\hline 8 & SAM & 17 & 3 & 17.6 & 0 & 0 & 14 & 82.4 & 9 & 7 & 77.8 & 0 & 0 & 2 & 22.2 \\
\hline 9 & PIP & 20 & 11 & 55 & 0 & 0 & 9 & 45 & 10 & 9 & 90 & 0 & 0 & 1 & 10 \\
\hline 10 & TZP & 17 & 0 & 0 & 0 & 0 & 17 & 100 & 9 & 8 & 88.9 & 0 & 0 & 1 & 11.1 \\
\hline \multicolumn{16}{|c|}{ Beta-lactam Cephalosporin } \\
\hline \multicolumn{16}{|c|}{ Generasi ke-1 } \\
\hline 11 & CEP & 21 & 0 & 0 & 0 & 0 & 21 & 100 & 8 & 7 & 87.5 & 0 & 0 & 1 & 12.5 \\
\hline
\end{tabular}




\begin{tabular}{|c|c|c|c|c|c|c|c|c|c|c|c|c|c|c|c|}
\hline 12 & $\mathrm{KZ}$ & 1 & 0 & 0 & 0 & 0 & 1 & 100 & 0 & 0 & 0 & 0 & 0 & 0 & 0 \\
\hline 13 & LEX & 2 & 1 & 50 & 0 & 0 & 1 & 50 & 0 & 0 & 0 & 0 & 0 & 0 & 0 \\
\hline \multicolumn{16}{|c|}{ Generasi ke-2 } \\
\hline 14 & FOX & 18 & 11 & 61.1 & 1 & 5.6 & 6 & 33.3 & 10 & 8 & 80 & 1 & 10 & 1 & 10 \\
\hline \multicolumn{16}{|c|}{ Generasi ke-3 } \\
\hline 15 & CAZ & 21 & 0 & 0 & 0 & 0 & 21 & 100 & 10 & 8 & 80 & 0 & 0 & 2 & 20 \\
\hline 16 & CTX & 14 & 11 & 78.6 & 0 & 0 & 3 & 21.4 & 6 & 5 & 83.3 & 0 & 0 & 1 & 16.7 \\
\hline 17 & $\mathrm{CRO}$ & 1 & 0 & 0 & 0 & 0 & 1 & 100 & 1 & 0 & 0 & 0 & 0 & 1 & 100 \\
\hline 18 & SCF & 19 & 15 & 78.9 & 1 & 5.3 & 3 & 15.8 & 9 & 8 & 88.9 & 0 & 0 & 1 & 11.1 \\
\hline \multicolumn{16}{|c|}{ Generasi ke-4 } \\
\hline 19 & FEP & 21 & 0 & 0 & 0 & 0 & 21 & 100 & 0 & 0 & 0 & 0 & 0 & 0 & 0 \\
\hline \multicolumn{16}{|c|}{ Folate pathway antagonist } \\
\hline 20 & SXT & 18 & 3 & 16.7 & 1 & 5.6 & 14 & 77.8 & 10 & 8 & 80 & 0 & 0 & 2 & 20 \\
\hline 21 & STX & 1 & 0 & 0 & 0 & 0 & 1 & 100 & 0 & 0 & 0 & & 0 & 0 & 0 \\
\hline \multicolumn{16}{|c|}{ Tetracyclin } \\
\hline 22 & $\mathrm{TE}$ & 21 & 18 & 85.7 & 0 & 0 & 3 & 14.3 & 10 & 9 & 90 & 0 & 0 & 1 & 10 \\
\hline 23 & TGC & 19 & 3 & 15.8 & 0 & 0 & 16 & 84.2 & 9 & 7 & 77.8 & 0 & 0 & 2 & 22.2 \\
\hline \multicolumn{16}{|c|}{ Chloramphenicol } \\
\hline 24 & $\mathrm{C}$ & 18 & 0 & 0 & 0 & 0 & 18 & 100 & 8 & 1 & 12.5 & 1 & 12.5 & 6 & 75 \\
\hline \multicolumn{16}{|c|}{ Macrolides } \\
\hline 25 & $\mathrm{E}$ & 19 & 1 & 5.3 & 1 & 5.3 & 17 & 89.5 & 10 & 5 & 50 & 2 & 20.0 & 3 & 30 \\
\hline 26 & TEC & 19 & 11 & 57.9 & 5 & 26.3 & 3 & 15.8 & 10 & 9 & 90 & 0 & 0 & 1 & 10 \\
\hline \multicolumn{16}{|c|}{ Quinolone } \\
\hline 27 & CIP & 1 & 0 & 0 & 0 & 0 & 1 & 100 & 0 & 0 & 0 & 0 & 0 & 0 & 0 \\
\hline 28 & LEV & 0 & 0 & 0 & 0 & 0 & 0 & 0 & 1 & 1 & 100 & 0 & 0 & 0 & 0 \\
\hline 29 & MXF & 20 & 10 & 50 & 0 & 0 & 10 & 50 & 10 & 5 & 50 & 0 & 0 & 5 & 50 \\
\hline \multicolumn{16}{|c|}{ Others } \\
\hline 30 & FOS & 20 & 2 & 10 & 0 & 0 & 18 & 90 & 9 & 3 & 33.3 & 0 & 0 & 6 & 66.7 \\
\hline 31 & IPM & 3 & 2 & 66.7 & 0 & 0 & 1 & 33.3 & 0 & 0 & 0 & 0 & 0 & 0 & 0 \\
\hline 32 & MEM & 14 & 11 & 78.6 & 1 & 7.1 & 2 & 14.3 & 8 & 7 & 87.5 & 1 & 12.5 & 0 & 0 \\
\hline 33 & ETP & 1 & 0 & 0 & 0 & 0 & 1 & 100 & 0 & 0 & 0 & 0 & 0 & 0 & 0 \\
\hline 34 & $\mathrm{~F}$ & 21 & 13 & 61.9 & 1 & 4.8 & 7 & 33.3 & 10 & 9 & 90 & 0 & 0 & 1 & 10 \\
\hline
\end{tabular}

Description: S=Sensitive; I=Intermediate; $\mathrm{R}=$ Resistant; $\mathrm{AMI}=$ Amikacin; $\mathrm{TOB}=$ Tobramycin; $\mathrm{CN}=$ Gentamicin; STM=Streptomisin; $\mathrm{ATM}=$ Aztreonam; $\quad \mathrm{AMC}=$ Amoxicillin-clavulanic $\quad$ acid; $\quad \mathrm{AMP}=$ Ampicillin; $\quad \mathrm{SAM}=$ Ampicillin-sulbactam; $\quad \mathrm{PIP}=\mathrm{Piperacillin}$; $\mathrm{TZP}=$ Piperacillin-tazobactam; $\quad \mathrm{CEP}=$ Cephalothin; $\quad \mathrm{KZ}=$ Cefazolin; $\quad \mathrm{LEX}=$ Cephalexin; $\quad \mathrm{FOX}=$ Cefoxitin; $\quad$ CAZ $=$ Ceftazidime; $\mathrm{CTX}=$ Cefotaxime; $\mathrm{CRO}=$ Ceftriaxone; $\mathrm{SCF}=$ Cefoperazone-sulbactam; $\mathrm{FEP}=$ Cefepime; $\mathrm{SXT}=$ Cotrimoxazole; $\mathrm{STX}=$ Trimethoprimsulfamethoxazole; TE=Tetracycline; TGC=Tigecycline; $\mathrm{C}=$ Chloramphenicol; $\mathrm{E}=$ Erythromycin; TEC=Teicoplanin; $\mathrm{CIP}=\mathrm{Ciprofloxacin}$; LEV=Levofloxacin; MXF=Moxifloxacin; FOS=Fosfomycin; IPM=Imipenem; MEM=Meropenem; ETP=Ertapenem; F=Nitrofurantoin.

\section{Discussion}

Table 1. shows that CAUTI patients caused by Escherichia coli at the intensive care unit of Dr. Soetomo General Academic Hospital based on gender group 25 (80.6\%) patients were female and $6(19.4 \%)$ patients were male. Previous research at the Surgical Intensive Care Unit (SICU) Serbia, stated that female sex was a significant risk factor in the incidence of CAUTI [7]. Another study stated that 6 out of 11 samples of ICU patients, who used a urethral catheter and confirmed positive for UTI, was female [8]. Women have a shorter urethra and are closer to the vaginal and anal spaces. Bacteria that ascend to the renal parenchyma via the ureters often cause pyelonephritis [9]. 
In addition to anatomical factors in women, immune system factors also affect the occurrence of UTIs in patients in intensive care. Urinary tract infections have suffered by more than $50 \%$ of women during their lifetime and $20 \%$ of them can become recurrent infections. Recurrent urinary tract infections are re-infection or recurrence of 3 UTIs within 12 months or 2 UTIs within 6 months [10]. Patients who are admitted to the intensive care unit regularly have underlying diseases, such as heart disease, lung disease, immune disorders, post-transplantation, and cancer resulting in increased treatment costs, morbidity, and mortality [11]. Recurrent UTIs commonly occur in patients with risk factors for immunodeficiency [12].

Table 2. shows that CAUTI patients caused by Escherichia coli at the intensive care unit of Dr. Soetomo General Academic Hospital by age group; dominated by 9 (29\%) elderly patients aged $46-65$ years, and at least $1(3.2 \%)$ toddler patients aged $5-11$ years. Previous research stated that at the intensive care unit of $\mathrm{H}$. Adam Malik Hospital and USU Medan Hospital, the incidence of CAUTI was dominated by 16 of 54 (29.6\%) patients aged 41-50 years and over 60 years [13]. Patients who used a permanent urethral catheter, those aged over 60 years were 2.2 times more likely to develop CAUTI than those aged less than 20 years [14]. Increasing age is a factor that has been shown to be associated with an increased prevalence of UTI. It is associated with altered estrogen status, urinary and fecal incontinence, pelvic organ prolapse, and bladder dysfunction [15]. Non-anatomical factors in men aged less than 1 year and elderly with prostatic hypertrophy contribute to the occurrence of more severe infections supported by other conditions, such as diabetes, use of urethral catheters, and spinal cord injury [9].

Aseptic principles need to be considered in intensive care patients, especially elderly patients who require treatment using a urethral catheter. Things that can be done to reduce the occurrence of CAUTI, namely aseptic urethral catheter insertion techniques, use of prophylactic antibiotics recommended by the local microbiology department according to microbial patterns and antibiotic sensitivity, regular replacement of urethral catheters according to type, and suprapubic catheter position for those requiring long-term drainage [16]. Factors that cannot be controlled by health workers need to be considered if preventive measures have been taken, but urinary tract infections still occur due to the use of urethral catheters. These factors, namely contamination of the urethral catheter due to direct contact from the patient's hands, patient feces, and other unconscious contamination.

Table 3. shows that CAUTI patients caused by Escherichia coli at the intensive care unit of Dr. Soetomo General Academic Hospital based on ESBL-producing and non-ESBL-producing groups showed Escherichia coli $21(67.7 \%)$ ESBL-producing groups and $10(32.3 \%)$ non-ESBL groups. ESBL is a beta-lactamase enzyme that can hydrolyze penicillins, monobactams (aztreonam) and most cephalosporins. Supporting factors for the occurrence of resistant ESBL organisms are previous use of beta-lactam antibiotics, long-term care in a health facility, previous invasive procedures, such as the use of urethral catheters, and comorbidities [17].

A study conducted showed that $81.5 \%$ of the 291 infection patients were patients with urinary tract infections caused by the ESBL-producing Escherichia coli [5]. Research conducted in 41 hospital laboratories throughout Indonesia in 2018 showed 1747 of 8318 (21\%) Escherichia coli isolates were Escherichia coli producing ESBL and $772(44 \%)$ were urine isolates. In addition, $89 \%$ are adult patients and $74 \%$ are inpatients [18]. The multicenter observational study stated that $61.9 \%$ of pathogenic microorganisms that cause infection in intensive care unit are Escherichia coli recorded by Antimicrobial Resistance (AMR), and 42 of 346 (12.1\%) patients with infections acquired in intensive care unit are CAUTI patients [19]. 
Table 4. shows that $85.7 \%$ ESBL-producing Escherichia coli are sensitive to tetracycline antibiotics. NonESBL Escherichia coli are 100\% sensitive to aminoglycoside and quinolone antibiotics, $90 \%$ are sensitive to tetracycline antibiotics, macrolides, and others. $80 \%$ sensitive to folate pathway antagonist antibiotics. Thirdgeneration cephalosporins and carbapenems were the main antibiotics given to symptomatic CAUTI patients in the ICU [20]. Pharmacological treatment options in organisms that can produce ESBLs are carbapenems (imipenem and meropenem) and cefamycin (cefoxitin and cefotetan). Other options that can fight ESBLproducing Enterobacteriaceae are ceftazidime-avibactam and ceftolozane-tazobactam which are the newest beta-lactamase inhibitors [17]. More than $90 \%$ of ESBL-producing Escherichia coli are sensitive to antibiotics tigecycline, amikacin, meropenem, ertapenem, and doripenem [18].

Table 4. also shows that there are several antibiotics that are intermediate to ESBL-producing and nonESBL-producing Escherichia coli, namely $26.3 \%$ intermediates to teicoplanin antibiotics and $22.2 \%$ intermediates to amikacin antibiotics. The clinical use of antibiotics which are classified as intermediates requires special attention. The scope of antibiotics that are still sensitive and used clinically in intensive care patients with infections needs to be considered. Delayed use of antibiotic therapy in infectious patients in the intensive care unit can lead to a significant increase in mortality. However, the provision of broad-spectrum antibiotics as prophylaxis in patients in the intensive care unit needs to be adjusted to the microbial pattern and antibiotic sensitivity of the local environment [21].

\section{Conclusion}

CAUTI patients caused by Escherichia coli at the intensive care unit of Dr. Soetomo General Academic Hospital during the January 2018-December 2019 period was dominated by female patients, elderly patients aged 46-65 years. Escherichia coli are dominated by ESBL-producing groups that are sensitive to tetracycline antibiotics. Non-ESBL Escherichia coli are sensitive to tetracycline antibiotics, aminoglycosides, quinolones, macrolides, and folate pathway antagonists. Inappropriate use of antibiotics has an impact on the rapid spread of antibiotic-resistant microorganisms in the intensive care environment in the future.

\section{Acknowledgements}

The researcher would like to thank the Faculty of Medicine, Airlangga University and Dr. Soetomo General Academic Hospital for providing facilities and support for this research.

\section{References}

[1] Gaid, E., Assiri, A., McNabb, S., \& Banjar, W., 2018. Device-Associated Nosocomial Infection in General Hospitals, Kingdom of Saudi Arabia, 2013-2016, Journal of Epidemiology and Global Health 7 (Suppl 1), pp. S35-S40. https://doi.org/10.1016/j.jegh.2017.10.008.

[2] McLellan, L. K., \& Hunstad, D. A., 2016. Urinary Tract Infection: Pathogenesis and Outlook, Trends in Molecular Medicine 22(11), pp. 946-957. https://doi.org/10.1016/j.molmed.2016.09.003.

[3] Behzadi, P., Behzadi, E., Yazdanbod, H., Aghapour, R., Cheshmeh, M. A., \& Omran, D. S., 2010. A Survey on Urinary Tract Infections Associated with the Three Most Common Uropathogenic Bacteria, Maedica 5(2), pp. 111-115.

[4] Sheik, G. B., Sannat, A., Al-Rowis, B., Jeddawy, S. M., \& M.Sherif, D., 2016. Prevalence, Risk Factors and Antimicrobial Susceptibility of Beta Lactamase Producing Enterobacteriacea in a Tertiary Care Centre of Saudi Arabia, International Journal of Current Microbiology and Applied Sciences 5(2), pp. 98-109. https://doi.org/10.20546/ijcmas.2016.502.011.

[5] Tonolini, M., 2018. Introduction to Urinary Tract Infections: An Overview on Epidemiology, Risk Factors, Microbiology and Treatment Options in "Imaging and Intervention in Urinary Tract Infections and Urosepsis," Springer International Publishing. Cham. https://doi.org/10.1007/978-3-319-68276-1. 
2018. Uncomplicated and Complicated Urinary Tract Infections in Adults: The Infectious Diseases's Specialist Perspective in "Imaging and Intervention in Urinary Tract Infections and Urosepsis," Springer International Publishing. Cham. https://doi.org/10.1007/978-3-319-68276-1.

[6] Niranjan, V., \& Malini, A., 2014. Antimicrobial Resistance Pattern in Escherichia coli Causing Urinary Tract Infection Among Inpatients, The Indian Journal of Medical Research 139(6), pp. 945-948.

[7] Mladenović, J., Veljović, M., Udovicić, I., Lazić, S., Segrt, Z., Ristić, P., \& Suljagić, V., 2015. Catheter-Associated Urinary Tract Infection in A Surgical Intensive Care Unit, Vojnosanitetski Pregled 72(10), pp. 883-888. https://doi.org/10.2298/vsp140624078m.

[8] Afrilina, I., Erly, E., \& Almurdi, A., 2017. Identifikasi Mikroorganisme Penyebab Infeksi Saluran Kemih pada Pasien Pengguna Kateter Urine di ICU RSUP Dr. M. Djamil Padang Periode 01 Agustus-30 November 2014, Jurnal Kesehatan Andalas 6(1), p. 196. https://doi.org/10.25077/jka.v6i1.670.

[9] McAninch, J. W., \& Lue, T. F., 2020. Bacterial Infections of The Genitourinary Tract, in "Smith \& Tanagho's General Urology 19 McGraw-Hill Education. New York.

[10] Yang, B., \& Foley, S., 2020. Introduction in "Female Urinary Tract Infections in Clinical Practice," Springer International Publishing. Cham. https://doi.org/10.1007/978-3-030-27909-7.

[11] Varon, J., 2016. Infectious Diseases in "Handbook of Critical and Intensive Care Medicine $4^{\text {th }}$," Springer International Publishing. Cham. https://doi.org/10.1007/978-3-319-31605-5.

[12] Jhang, J. F., \& Kuo, H. C., 2017. Recent advances in recurrent urinary tract infection from pathogenesis and biomarkers to prevention, Tzu Chi Medical Journal 29(3), pp. 131-137. https://doi.org/10.4103/tcmj.tcmj_53_17.

[13] Anggi, A., Wijaya, D. W., \& Ramayani, O. R., 2019. Risk Factors for Catheter-Associated Urinary Tract Infection and Uropathogen Bacterial Profile in the Intensive Care Unit in Hospitals in Medan, Indonesia, Open Access Macedonian Journal of Medical Sciences 7(20), pp. 3488-3492. https://doi.org/10.3889/oamjms.2019.684.

[14] Aly, S. A., Tawfeek, R. A., \& Mohamed, I. S., 2016. Bacterial Catheter-Associated Urinary Tract Infection in The Intensive Care Unit of Assiut University Hospital, Al-Azhar Assiut Medical Journal 14(2), pp. 52-58. https://doi.org/10.4103/16871693.192652 .

[15] Mulvey, M. A., Klumpp, D. J., \& Stapleton, A. E., 2017. Anatomy and Physiology of The Urinary Tract: Relation to Host Defense and Microbial in "Urinary Tract Infections: Molecular Pathogenesis and Clinical Management $2^{\text {nd }}$," ASM Press. Washington DC.

[16] Rané, A., \& Dasgupta, R., 2013. Catheter-Associated Urinary Tract Infections in "Urinary Tract Infection: Clinical Perspectives on Urinary Tract Infection," Springer. London. https://doi.org/ 10.1007/978-1-4471-4709-1.

[17] Mayer, S. A., Shapiro, J. M., Gidwani, U. K., \& Oropello, J. M., 2020. Antimicrobial Therapy, in "Critical Care Mount Sinai Expert Guides," Wiley-Blackwell. Hoboken. https://doi.org/10.1002/9781119293255.ch10.

[18] Dahesihdewi, A., Dewi, Y. P., Sugianli, A. K., \& Parwati, I., 2019. "Extended Spectrum B-lactamase (ESBL) in Review Surveilans Bakteri Resistan Multi Obat dan Kepekaannya Terhadap Antibiotik di Rumah Sakit Indonesia Tahun 2018," Departemen Patologi Klinik dan Kedokteran Laboratorium Fakultas Kedokteran Kesehatan Masyarakat dan Keperawatan. Yogyakarta.

[19] Venkataraman, R., Divatia, J. V., Ramakrishnan, N., Chawla, R., Amin, P., Gopal, P., Chaudhry, D., Zirpe, K., \& Abraham, B., 2018. Multicenter Observational Study to Evaluate Epidemiology and Resistance Patterns of Common Intensive Care Unitinfections, Indian Journal of Critical Care Medicine 22(1), pp. 20-26. https://doi.org/10.4103/ijccm.IJCCM_394_17.

[20] Ding, R., Li, X., Zhang, X., Zhang, Z., \& Ma, X., 2019. The Epidemiology of Symptomatic Catheter-Associated Urinary Tract Infections in The Intensive Care Unit: A 4-year Single Center Retrospective Study, Urology Journal 16(3), pp. $312-317$. https://doi.org/10.22037/uj.v0i0.4256.

[21] Karam, G., Chastre, J., Wilcox, M. H., \& Vincent, J. L., 2016. Antibiotic Strategies in The Era of Multidrug Resistance, Critical Care 20(1), p. 136. https://doi.org/10.1186/s13054-016-1320-7. 